\title{
Mediação de Conflitos Socioambientais no Paraná: Mineração e Impactos à Saúde Pública
}

\author{
Mediation of Socio-environmental Conflicts in Paraná: Mining \\ and Impacts on Public Health
}

\author{
Andreza Portella Ribeiro [a] (iD), Mauro Silva Ruiz [b] [D], \\ Tatiana Tucunduva Philippi Cortese [a] [D], Leonardo Ferreira da Silva [a] [D. \\ Sidnei Aranha [c] [D], Maria Laura Fogaça Zei [a] [D]
}
[a] Universidade Nove de Julho, Programa de Mestrado em Cidades Inteligentes e Sustentáveis, São Paulo, SP, Brasil
[b] Espiral Educação e Assessoria Ltda, Rio Claro, SP, Brasil
[c] Prefeitura de Guarujá, Secretaria Municipal do Meio Ambiente, Guarujá, SP, Brasil

\begin{abstract}
Como citar: Ribeiro, A. P., Ruiz, M. S., Cortese, T. T. P., Silva, L. F., Aranha, S., \& Zei, M. L. F. (2021). Mediação de conflitos socioambientais no Paraná: mineração e impactos à saúde pública. urbe. Revista Brasileira de Gestão Urbana, v. 13, e20200318. https://doi.org/10.1590/2175-3369.013.e20200318
\end{abstract}

\section{Resumo}

Conflitos socioambientais resultam de pressões antrópicas sobre o meio ambiente e refletem questões sociais e políticas, principalmente onde o poder público não ascende com soluções para atender às necessidades dos cidadãos. Embora exista relevante literatura científica brasileira, nesta priorizam-se estudos de "diagnósticos", com lacuna de estudos direcionados à mediação por meio de modelos adaptados a embates, atores envolvidos e danos ambientais. Assim, apresenta-se uma análise sobre formas de mediação de conflitos, em São Mateus do Sul-PR, cidade que abriga uma indústria de mineração de xisto. Divergências a partir de reclamações dos moradores sobre problemas respiratórios levaram à proposição de uma ação judicial pelo Ministério Público do Paraná. Foi utilizado o Modelo Diagnóstico de Rondeau (1996), com intuito de analisar potenciais formas para explicar e, então, mediar o conflito, em alternativa à judicialização. Dados primários foram obtidos pela análise de conteúdo de Ações Civis Públicas protocoladas no Poder Judiciário/PR. Devido ao fato de os tribunais estarem repletos de casos da área ambiental sem solução, verifica-se a importância do estudo à proposição de abordagens de negociação para embates socioambientais, por meio de modelos teóricos com soluções em curto espaço de tempo.

Palavras-chave: Conflitos Socioambientais. Mineração. Modelo Diagnóstico de Rondeau. Poluição Ambiental. Saúde.

\section{Abstract}

Socio-environmental conflicts are issues result from anthropic pressure on the environment that reflect social and politics aspects, mostly where the public power does not provide solutions for the necessity of local citizens.

\footnotetext{
APR é professora e pesquisadora, doutora em Tecnologia Nuclear - Química Ambiental, e-mail: aportellar@gmail.com MSR é professor e pesquisador, doutor em Geografia, e-mail: maurosilvaruiz@gmail.com TTPC é professora e pesquisadora, doutora em Saúde Pública, e-mail: taticortese@gmail.com

LFS é pesquisador colaborador, mestre em Cidades Inteligentes e Sustentáveis, e-mail: leonardo.silva57@fatec.sp.gov.br SA é secretário municipal do meio ambiente, mestre em Gestão Ambiental, e-mail: sidneiaranhagja@gmail.com MLFZ é pesquisadora colaboradora, mestre em Cidades Inteligentes e Sustentáveis, e-mail: arqlaurazei@gmail.com
} 
In Brazil, there are relevant scientific works related to the theme. Most articles present a diagnostic regarding the conflict. There is a gap on studies based on theorical approaches that consider a specific case and the people involved in it. Accordingly, this paper takes into account São Mateus do Sul - PR, a city that hosts a shale mining plant. Disagreements from the citizen that claims on respiratory diseases resulted to a lawsuit by the Public Ministry of Paraná. The conflict was analyzed by Dynamic Analysis Rondeau Model (1996), to indicate other solutions, besides judicialization of conflicts. Primary data were obtained through the analysis of the content of public civil actions filed at Judiciary/PR. Take into account the challenge of the theme and the fact that the courts are filled of unsolved socio-environmental conflicts, this article brings an important issue: the evaluate of conflicts based on theorical approaches that might result in decision-makers in a short time.

Keywords: Socio-environmental conflicts. Mining, Diagnostic Model of Rondeau. Environmental Pollution. Health.

\section{Introdução}

Os processos de uso e ocupação do solo em cidades, ainda que planejados, podem evoluir diferentemente de sua concepção original, resultando em externalidades ambientais cujos efeitos podem afetar negativamente a população local. Essa evolução diferenciada pode resultar da própria expansão da malha urbana para bairros periféricos, influenciada pela especulação imobiliária, ou pode ser induzida pela implantação de empreendimentos industriais ou de infraestrutura (Jacobi \& Teixeira, 1995; Ruiz, Correa, Gallardo, \& Sintoni, 2014; Bernardelli-Junior, Ruiz, \& Gallardo, 2017).

Essa evolução, até certo ponto, pode ser benéfica à população; porém, em certas circunstâncias também pode gerar externalidades negativas que se desdobram em injustiças e/ou conflitos socioambientais.

A instalação de empreendimentos cujas atividades causam impactos significativos no meio ambiente, nas áreas periféricas de cidades, por vezes à revelia da população, também tem sido frequente no Brasil, geralmente envolvendo atividades de lavra e beneficiamento de minérios (Chagas, 2010; Corrêa, 2015), aterros sanitários e industriais, e usinas de incineração de resíduos (Jacobi, 1995) e obras de infraestrutura (Bernardelli-Junior et. al, 2017) dentre outros. Nesses casos surgem os conflitos socioambientais urbanos que, segundo Dias (2000), são conflitos resultantes da pressão antrópica sobre o meio ambiente urbano que refletem os conflitos sociais e políticos, principalmente onde o poder público não ascende com soluções para atender as necessidades dos cidadãos.

As injustiças ambientais verificadas têm origem nas desigualdades sociais. 0 maior potencial de danos, devido ao desenvolvimento socioeconômico, reflete sobre grupos raciais discriminados, populações de baixa renda, marginalizadas e vulneráveis (Herculano, 2002). A população mais pobre é geralmente menos informada, tem menor poder de barganha e, portanto, mais chances de ser injustiçada nas negociações (Rocha, 2012).

Um caso exemplar envolvendo atividade minerária é o da implantação em 1993 da mineradora de xisto Petróleo Brasileiro S/A SIX (Superintendência da Industrialização do Xisto) em SMS, objeto deste estudo. Se por um lado a mineradora impulsionou a economia local, por outro, vem causando externalidades negativas, poluição, que podem ser caracterizadas como conflitos socioambientais urbanos.

A atividade de mineração é considerada como um dos setores-chave da economia, responsável pela oferta de grande número de vagas de empregos diretos e indiretos, contribuindo para a geração de divisas e arrecadação de tributos, dentre outros aspectos favoráveis ao desenvolvimento, que vão além do espaço geográfico, onde a atividade operacional é desenvolvida (Oliveira- Neto \& Petter, 2005). Por outro lado, a exploração mineral causa impactos nos compartimentos ambientais, devendo ser considerados riscos à qualidade de vida da população que vive no entorno de sítios de mineração e esforços para mitigação (CPRM, 2005). Se considerados os aspectos positivos e negativos que acompanham qualquer atividade de mineração, as divergências de opiniões sobre sua viabilidade, frequentemente estabelecem uma arena de conflitos onde os atores envolvidos se sentem de alguma forma prejudicados e tais divergências se 
transformam em embates organizados, caracterizando-se em conflitos socioambientais (Ruiz, Correa, Gallardo, \& Sintoni, 2014).

Em relação à complexidade e a importância do tema, este artigo apresenta uma $r$ do caso, evidenciando as relações entre os principais atores e as medidas adaptativas (compulsórias) adotadas pela mineradora de xisto SIX, em SMS, objetivando alcançar a chamada sustentabilidade sensata, como destaca Enríquez (2006), e assim minimizar as externalidades negativas sofridas pela população local.

Tendo esse histórico de conflitos como referencial e a perspectiva de que formas de negociação alternativas à arbitragem possam ser ensejadas para o caso da SIX, são apresentadas duas questões de pesquisa:

1- Como se configuram os conflitos socioambientais relacionados à exploração do xisto em SMS?

2- Que outros instrumentos de negociações de conflitos, além dos judiciais, se apresentam como alternativas potenciais para a busca de solução aos embates socioambientais relacionados aos danos ambientais causados pelas atividades da SIX?

Para responder à primeira questão, os autores aplicam um modelo conceitual (Rondeau, 1996) à situação de conflito vivenciada em SMS. Já no que se refere à busca de respostas para satisfazer à segunda questão, foi observada uma acentuada limitação na aplicação de técnicas para a resolução de conflitos socioambientais no Brasil.

A literatura de conflitos socioambientais no Brasil é relativamente recente, pois a temática ganhou maior expressão a partir do estabelecimento das bases legais do licenciamento ambiental traçada, principalmente, na Lei 6.938/81 (Brasil, 1981), que dispõe sobre a Política Nacional do Meio Ambiente e traz um conjunto de normas para a preservação ambiental.

Embora uma quantidade razoável de artigos brasileiros já tenha sido publicada, em sua maioria tratam do diagnóstico de conflitos socioambientais. Observa-se uma "lacuna teórica" sobre negociações; são ínfimas a utilização de modelos teóricos que visam à adaptação para aplicação na análise e negociação de conflitos na área ambiental.

Tendo em perspectiva que atualmente as soluções negociadas de conflitos podem se tornar uma tendência no país, pelo fato de os tribunais estarem repletos de casos da área ambiental ainda sem solução, há espaço para a proposição de abordagens de negociação entre as partes envolvidas, em embates dessa natureza, fundamentadas em modelos já existentes na literatura. No âmbito deste estudo, propõe-se a adaptação da abordagem da análise dinâmica do modelo Diagnóstico de conflitos de Rondeau (1996), utilizado na análise de conflitos em organizações, para a busca de soluções negociadas entre a população de São Mateus do Sul, PR e a SIX.

Além de suprir em parte a lacuna teórica, considera-se que a adaptação da referida abordagem poderá ser útil no estabelecimento de estratégias de análises visando à busca de soluções negociadas para outros embates socioambientais ainda sem solução, sob a ótica da governança ambiental.

\section{Abordagens Teóricas sobre de conflitos socioambientais}

Existe uma grande variedade de abordagens sobre os conflitos socioambientais oferecendo grandes desafios para organizar sua teoria de forma concisa e clara. Notadamente, verifica-se que há uma relação frágil entre teoria, pesquisa e prática (Acselrad, 2004; Viégas, 2009). A literatura brasileira trata mais frequentemente da análise dos conflitos e muito pouco nas suas negociações ou resoluções. Para Bredariol (2004), não se verifica uma tradição em negociação de conflitos socioambientais em nosso país, embora estejam presentes na literatura como bases para a construção de políticas públicas pertinentes.

As abordagens teóricas atinentes à análise dos conflitos socioambientais podem ser classificadas em três tipos:

- Sociológica - relacionam-se com formas diferenciadas de apropriação de recursos gerando processos de exclusão e de reprodução de desigualdades sociais (Nascimento, 2001; Viégas, 2009); 
- Baseada na ecologia política - são expressões de tensão no processo de reprodução dos modelos de desenvolvimento (Fuks, 1998; Little, 2001);

- Histórica - interpreta os conflitos no contexto dos movimentos ambientalistas e da evolução das pressões sociais (Braga-Neto, 2008; Miranda, 2011).

Já no que se refere às abordagens objetivando a resolução dos conflitos, de maneira geral sugere-se a seguinte classificação:

- Construção de Consensos - posição de barganha versus foco nos interesses e MAPAN — Harvard (Fisher et al., 2011);

- Resolução Alternativa de Disputas - parcerias e iniciativas conjuntas para busca de soluções; Ato Administrativo nos EUA (Wondolleck, Manring, \& Crowfoot, 1996);

- Resolução de conflitos em Organizações - apresenta três tipos de abordagens: estrutural; diacrônica; e dinâmica (Rondeau, 1996).

Nas negociações de conflitos, o diálogo é fundamental, para que se tenha sinergia entre os atores envolvidos. Para tanto, os Ministério Público Federal e Estadual, bem como órgãos ambientais públicos vêm gradualmente atuando nos casos, buscando o cumprimento de compromissos estabelecidos, considerandose os instrumentos jurídicos que priorizam a preservação do meio ambiente e as questões sociais (BragaNeto, 2008).

Para Pasquino et al. (1986), observa-se uma tentativa à formulação de regras que contemplem, tanto quanto possível, os interesses das partes, estabelecendo-se, assim, limites de ganhos e perdas e, no caso de as regras serem modificadas durante a negociação, os atores devem estar de comum acordo.

A negociação de conflitos preconiza os ganhos mútuos, com acordos padronizados na forma de jogos de soma zero. Isto é, a busca por um equilíbrio em que um lado ganha e outro perde; mas, entre prós e contras, os resultados se anulam no balanço total, caracterizando uma resolução pacífica entre os envolvidos (Sollow, 1993).

Apesar dos instrumentos balizadores pautados na Constituição de 1988, os desafios inerentes à mediação de conflitos socioambientais permanecem, face às demandas por uma sociedade global sustentável (Cunha, 2006). Embora exista literatura que contemple a temática de conflitos socioambientais, aquelas voltadas à negociação ou formas de mediação ainda são ínfimas (Bredariol, 2004). Grande parte dos estudos brasileiros estão focados no diagnóstico e não na resolução dos conflitos.

Cumpre destacar que existe uma divergência em discutir mineração e questões socioambientais, visto que o ordenamento jurídico brasileiro, por meio do novo Código Florestal, considera a mineração uma atividade de utilidade pública ou de interesse social, porém é uma atividade causadora de impactos ambientais e sociais.

De um lado, as minas transformam os ambientes por meio da ocupação e transformação da terra para aproveitamento dos recursos naturais, promovendo o desenvolvimento regional, gerando empregos e desenvolvendo outros setores da economia e é fonte de tributos. Do outro, os impactos resultantes do uso ou desvio da água que modificam os regimes hídricos, o alto consumo de energia nas etapas de extração e beneficiamento dos minérios, grandes áreas desmatadas para construção de estradas de acesso, de barragens de rejeitos e clareiras para exploração, além da contaminação do solo por exposição de metais pesados (Werner et al., 2019).

Por ser fonte geradora de tributos fiscais, a mineração pode trazer ainda outro desafio que é a CFEM (Compensação Financeira pela Exploração de Recursos Minerais). A CFEM foi prevista no artigo 20 da Constituição Federal e regulamentada pelo Decreto 001/91 e é uma contraprestação paga à União pelo aproveitamento econômico dos recursos minerais. Esses recursos devem ser recolhidos e distribuídos aos Estados, Municípios e órgãos da Administração Pública e deverão ser aplicados em projetos que tragam benefícios para comunidade local, seja em melhorias de infraestrutura ou da qualidade ambiental.

Porém, se tal renda não for bem administrada, pode acentuar ainda mais os conflitos na região por aumento das desigualdades de renda, maior degradação ambiental, corrupção nos órgãos responsáveis pela administração pública e falta de efetividade das normas jurídicas existentes. E existe a necessidade de 
tornar mais rigorosa a aplicação do ordenamento jurídico brasileiro, fortalecendo as instituições de licenciamento, monitoramento e controle ambiental para um gerenciamento eficaz. Os impactos ambientais e sociais não podem ser impostos como condição para esta atividade econômica (Weiss, 2019).

0 que se verifica no Brasil é a gestão de conflitos fundamentada, essencialmente, em instrumentos judiciais. Como consequência, tem-se um grande acúmulo de processos aguardando definição. No âmbito político-ambiental existe uma tendência favorável à gestão de conflitos socioambientais, por meio de acordos tripartites que envolvem Estado, mercado e sociedade (Bredariol, 2004).

A resolução de conflitos via mediação é uma tendência em alguns países europeus e também nos Estados Unidos e Canadá (Camargo, 2007). A resolução tem como fundamento os direitos indisponíveis, que preconiza o envolvimento dos cidadãos (individual ou coletivamente). A formulação e execução da política ambiental são claras, com a participação de todos, entretanto, é importante destacar que a mediação de conflitos somente se verifica no âmbito dos direitos individuais (pessoa envolvida). Não se observa mediação na esfera dos direitos transindividuais ou coletivos, devido aos entraves referentes aos interesses adversos das partes envolvidas.

No Brasil, pode-se afirmar que a mediação de conflitos socioambientais se caracteriza como ferramenta promissora, que possibilita minimizar os custos financeiros e a frequência das audiências públicas, com a perspectiva de garantir elevado nível de cumprimento dos objetivos almejados entre as partes.

Na literatura brasileira, prevalecem os interesses políticos. As negociações são mencionadas, mas não há referências ao uso de metodologias de apoio à negociação. Os procedimentos são mencionados por VillasBoas (1995), Schmitt (1995), Jacobi \& Teixeira (1995), Dias \& Padovan (1995), Bredariol (1997), para a elaboração de acordos, escrituras de compromisso, mas não mencionam a utilização de metodologias de apoio às negociações. As questões relacionadas à equidade social são particularmente significativas, bem como o acesso a serviços e bens públicos, à democratização do Estado e à sustentabilidade ambiental, relacionadas à implementação de empreendimentos geradores de disputas (Bredariol \& Magrini, 2003).

\section{Ganha-ganha: a perspectiva de Rondeau}

Nos conflitos socioambientais os embates entre os atores envolvidos são complexos, dificultando o encaminhamento de soluções, por meio do diálogo e da busca do consenso, de modo que a situação mais comum é a busca da solução judicial. Via de regra, nas decisões judiciais as soluções são do tipo ganha-perde; ou seja, uma parte ganha, diferentemente da solução negociada, que é pela perspectiva ganha-ganha.

Fisher \& Ury (1985) enfatizam a abordagem ganha-ganha, visando acordos em negociações envolvendo corporações. Nessa mesma linha, Rondeau (1996) apresenta como abordagens possíveis as análises estrutural, dinâmica e diacrônica que resultam na elaboração de um "modelo diagnóstico", tendo em perspectiva a gestão desses embates, com vistas à mitigação de impactos, favorecendo e/ou facilitando a busca de soluções para todas as partes envolvidas, de maneira satisfatória (ganha-ganha).

A análise estrutural do conflito sugere que as partes envolvidas não exerçam influências entre si, exigindo um estudo exaustivo das condições a que estão submetidas, objetivando esclarecer aspectos associados às predisposições pessoais e previsões estratégicas comportamentais desenvolvidos pelas partes. Essa análise culmina na formulação de elementos de caráter normativo, denominado quadro de referência (Rondeau, 1996).

Inicialmente, na análise dinâmica proposta pelo autor, o conflito apresenta-se de forma equilibrada e, à medida que uma das partes desenvolve suas percepções em relação à outra, o equilíbrio vai se deteriorando. Trata-se de um processo interativo, no qual o comportamento de uma parte é parcialmente determinado pela reação da outra. A interação entre as partes é considerada mais importante que o contexto do conflito, pois estimula a busca da compreensão dos problemas que envolvem as partes, seus comportamentos e intenções.

A análise diacrônica de Rondeau (1996) presume que as percepções das partes vão se modificando à medida que o conflito progride. Nessa análise, a escalada do conflito (ou sua desaceleração) ao longo do 
tempo deve prevalecer frente ao desdobramento final do evento em si. Desse modo, os atores poderão diminuir sua hostilidade recíproca e reprimir sua deterioração perceptiva mútua. Talvez se torne necessária a intervenção de uma terceira parte, com vistas à reestruturação do equilíbrio dos envolvidos, de forma mais satisfatória para ambos os lados.

\section{Metodologia}

O estudo é de natureza qualitativa, com abordagens descritiva e exploratória, com base no método do estudo de caso (Yin, 2010): a exploração de xisto em SMS e os conflitos decorrentes dos impactos socioambientais dessa atividade.

As fontes de evidências para a consecução do estudo de caso originaram-se de dados secundários, com levantamento documental e pesquisa bibliográfica. Para tanto, o estudo baseou-se prioritariamente, na análise do relatório pericial de Rech (2010) e em sites especializados contendo informações sobre legislação ambiental e minerária, ações civis públicas (ACP) e termos de ajustamento de conduta (TAC). A pesquisa bibliográfica baseou-se em artigos publicados em periódicos científicos (Ferreira et al., 2017) e em tese de doutorado (Watanabe, 2010).

A ACP foi proposta pelo Ministério Público do Paraná (MP-PR) com pedido de liminar em desfavor de Petróleo Brasileiro S/A - SIX, em janeiro de 2013 (processo 338-13.2013.8.16.0158). Por se tratar de um processo digital e público, a consulta pôde ser realizada no site do Processo Eletrônico do Judiciário do Paraná - PROJUDI / Tribunal de Justiça do Paraná (TJ-PR, 2006).

\section{Área de Estudo}

São Mateus do Sul - PR está localizada a $140 \mathrm{~km}$ de Curitiba e a $65 \mathrm{~km}$ de Irati (Figura 1). 0 município ocupa uma área de $1.341,714 \mathrm{~km}^{2}$, com 41.257 habitantes e densidade populacional de 30,75 habitantes $/ \mathrm{km}^{2}$ (IBGE, 2010).

A região foi colonizada em 1877, por poloneses, tendo como principais atividades a agricultura e o extrativismo (de madeira e erva-mate). Em meados do século passado, esta região vivenciou quase duas décadas de estagnação econômica, com prejuízos à manutenção da vida dos moradores.

A retomada do crescimento ocorreu no final dos anos 1960, quando a Petrobras decidiu implantar uma usina experimental para o aproveitamento do xisto. A mineração impulsionou o desenvolvimento industrial e socioeconômico de SMS. Atualmente o município ocupa a 19a posição (estadual) relativa à arrecadação do Imposto sobre Circulação de Mercadorias e Serviços (ICMS, de um total de 399 cidades, sendo que a atividade econômica está dividida entre agricultura e serviços (40\%) e indústria (60\%) (PMSMS, 2015).

0 xisto é considerado fonte potencial de hidrocarbonetos. Do "minério de xisto ${ }^{1 "}$ " se extrai o óleo com os mesmos derivados do petróleo de poço e subprodutos que são matéria-prima para diversos segmentos industriais (Petrobras, 2009). No Brasil, o xisto é encontrado em diferentes regiões, a maior parte localizase na Formação de Irati, que compreende os estados de Goiás, Mato Grosso do Sul, São Paulo, Paraná, Santa Catarina e Rio Grande do Sul. A Petrobras intensificou suas pesquisas para exploração do xisto nas jazidas de SMS (Petrobras, 2009).

Em 1973, a mineradora já processava 1 t/dia de xisto. Em 1993, foi implantado o Parque Tecnológico da SIX, reconhecido mundialmente como o mais avançado no aproveitamento industrial desse minério (Petrobras, 2009).

\footnotetext{
${ }^{1}$ Em termos geológicos, denominação imprópria, pois xisto é uma rocha metamórfica com alinhamento de minerais planares, geralmente mica, em função dos efeitos do metamorfismo sobre ela. Na verdade, xisto é um folhelho betuminoso, uma rocha sedimentar impregnada de um material oleoso, oriundo de matéria orgânica, que se formou concomitante à rocha, mas que não teve condições de migrar para uma rocha armazenadora como por exemplo, arenito.
} 
Embora a SIX tenha impulsionado o desenvolvimento de SMS e arredores, questões ambientais motivaram divergências de opiniões entre os moradores sobre a relação custo-benefício do empreendimento na cidade. Dessa forma, a cronologia dos fatos e seus desdobramentos serão apresentados e discutidos nas sessões seguintes.

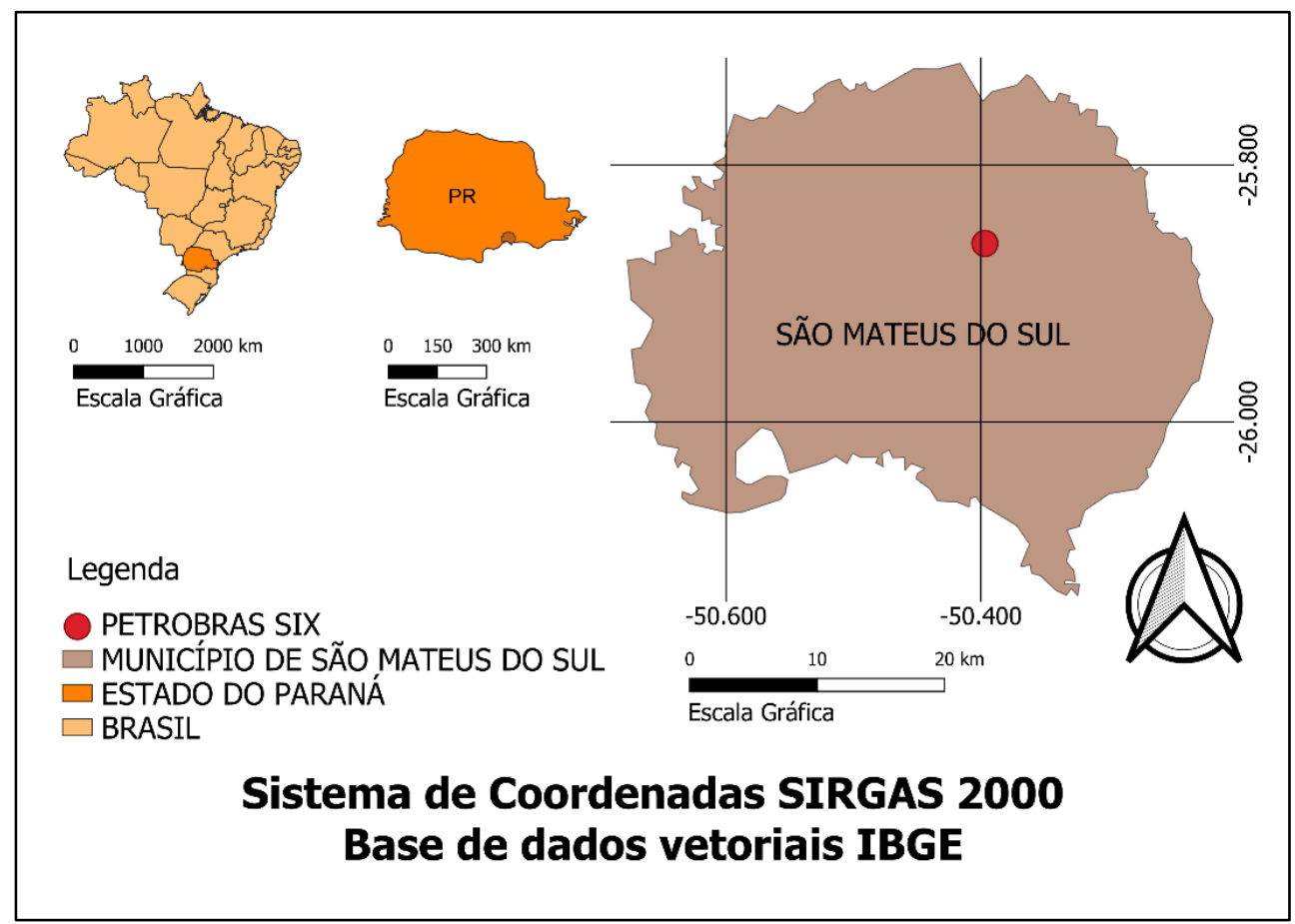

Figura 1 - Localização Geográfica de São Mateus do Sul - PR., e da Petrobras SIX, dentro do município. Fonte: Autores (2020).

\section{Resultados}

Não obstante às vantagens socioeconômicas supracitadas, ocorre que SMS se expandiu em direção à mineradora, de modo que a população passou a ser afetada pelas emissões de material particulado, rico em substâncias químicas potencialmente tóxicas. Diante do aumento da incidência de doenças respiratórias, em 2000, iniciaram-se as divergências de interesses entre a SIX e uma parcela de moradores, que culminou na abertura do procedimento investigatório preliminar pelo Ministério Público Estadual.

Em setembro de 2002, a Petrobras procurou o Instituto Ambiental do Paraná (IAP) para comunicar possível contaminação dentro do seu complexo industrial. Em outubro de 2002, o IAP firmou com a Petrobras um termo de compromisso para que esta realizasse estudos e análise de efeitos ambientais de sua operação e, em dezembro do mesmo ano, foi firmado um TAC ${ }^{2}$ com a Petrobras contraindo a obrigação de realizar ações de remedição e recuperação da área afetada. Em março de 2005 foi firmado um Termo Aditivo, estendendo prazos e medidas; porém, a empresa não cumpriu o compromisso de controlar a poluição ambiental e de recuperar as áreas degradadas (MPE, 2013).

Pesquisas conduzidas entre 2005 e 2009 sobre a contaminação do ar em SMS indicaram níveis preocupantes de metais como ferro, óxidos de enxofre no material particulado (Ferreira et al., 2017; Ribeiro et al., 2017). Pode-se inferir a degradação ambiental e a constatação de que a saúde da população era diretamente afetada (Ferreira et al., 2017; Ribeiro et al., 2017), ensejando a instauração do inquérito civil no 01/2010 e em janeiro de 2013, a proposição de Ação Civil Pública, objetivando a adequação da operação da SIX (MPE, 2013).

Frente ao histórico do conflito, a promotora de justiça do MP-PR, Fernanda Basso Silvério, entrou com uma ação civil pública, solicitando a interdição da SIX e o pagamento de multas indenizatórias (MPE, 2013),

${ }^{2}$ Lei 7347 de 24 de julho de 1985, art. 5ㅇ․ 
sendo essa liminar negada, havendo o juiz ponderado que a suspensão das atividades da ré causaria “(...) prejuízo social bastante elevado, com desemprego em massa, desaceleração da economia local e diminuição das receitas públicas (...)" (MPE, 2013, p. 6).

A Petrobras apresentou sua contestação em audiência de conciliação, em 19 de agosto de 2014. Nesta, ficou determinado que a investigação deveria ser feita por perito de órgão público, para produzir provas relevantes de maneira mais célere. No entanto, após 2.264 dias em tramitação, o conflito segue sem uma solução, que permita o desenvolvimento socioeconômico da região, com a proteção dos recursos ambientais e saúde da população local. 0 processo se encontra atualmente suspenso. 0 cenário descrito sobre o conflito socioambiental em SMS, considerando os principais atores envolvidos é esquematizado na Figura 2.

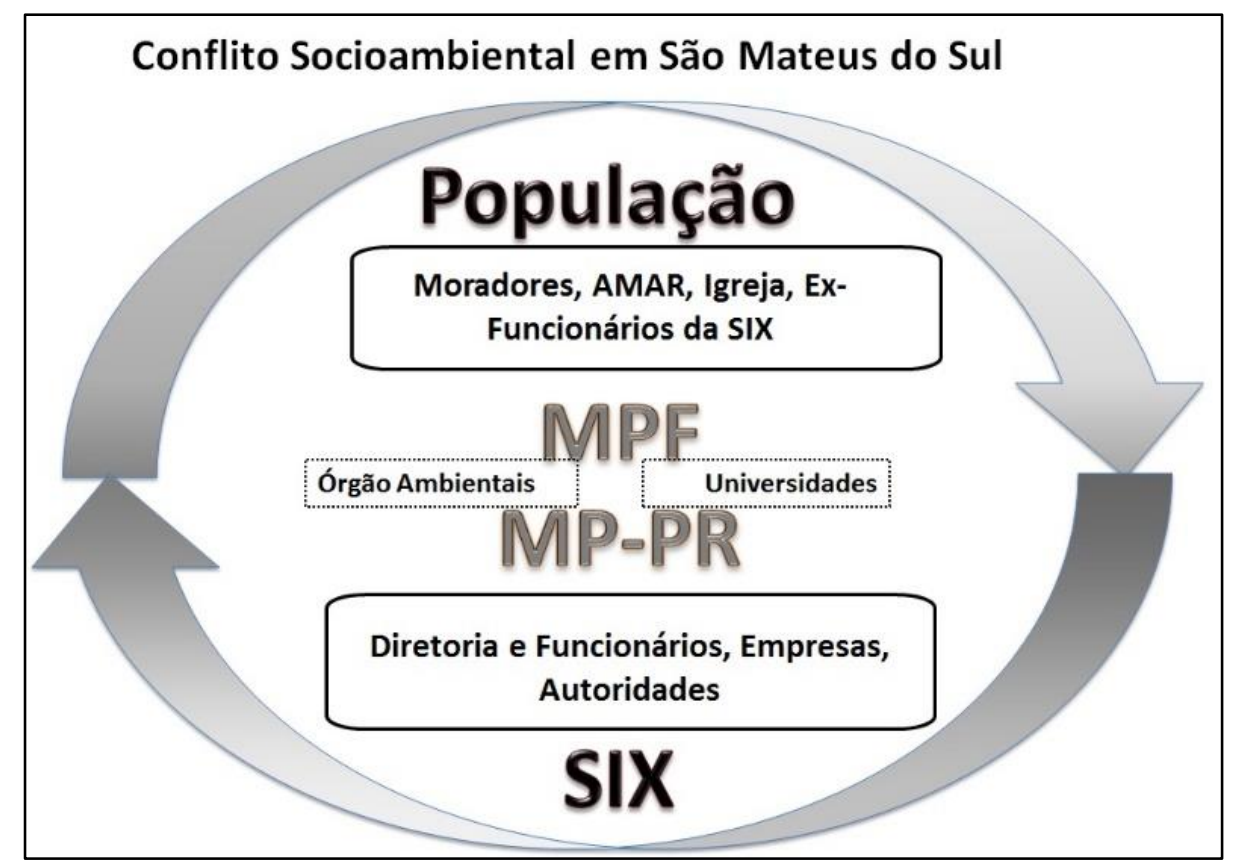

Figura 2 - Atores envolvidos no conflito socioambiental devido à contaminação ambiental em de SMS. Fonte: Adaptado de Rondeau (1996).

\section{Aplicação do modelo Diagnóstico de Rondeau (1996)}

Diante do conflito evidenciado em SMS, verifica-se que a Análise Diacrônica do Modelo de Rondeau (Figura 3a) é a que menos se ajusta à situação. É possível afirmar que a partir do momento em que a Petrobras não cumpriu o TAC, de certa forma, houve uma quebra da comunicação "mediada" pelo IAP, entre a empresa e a população local (Figura 3b). Isso pode ser visto como uma "incompatibilidade entre as partes", que resultou no ajuizamento da ação civil pública no MPF. Conforme prevê o Modelo, tal incompatibilidade, provavelmente atingiria o status de "cisão" total, resultando na interrupção das atividades de mineração. Entretanto, dada a importância socioeconômica da planta industrial, o juiz da Vara Cível da Comarca de SMS indeferiu a liminar que solicitava o fechamento imediato da SIX, ele entendeu que a descontinuidade das suas atividades afetaria diretamente um grande número de moradores e trabalhadores da SIX e, indiretamente, na economia local, pelo fato de a mineradora gerar diversos outros postos de trabalho (Aníbal, 2013). 


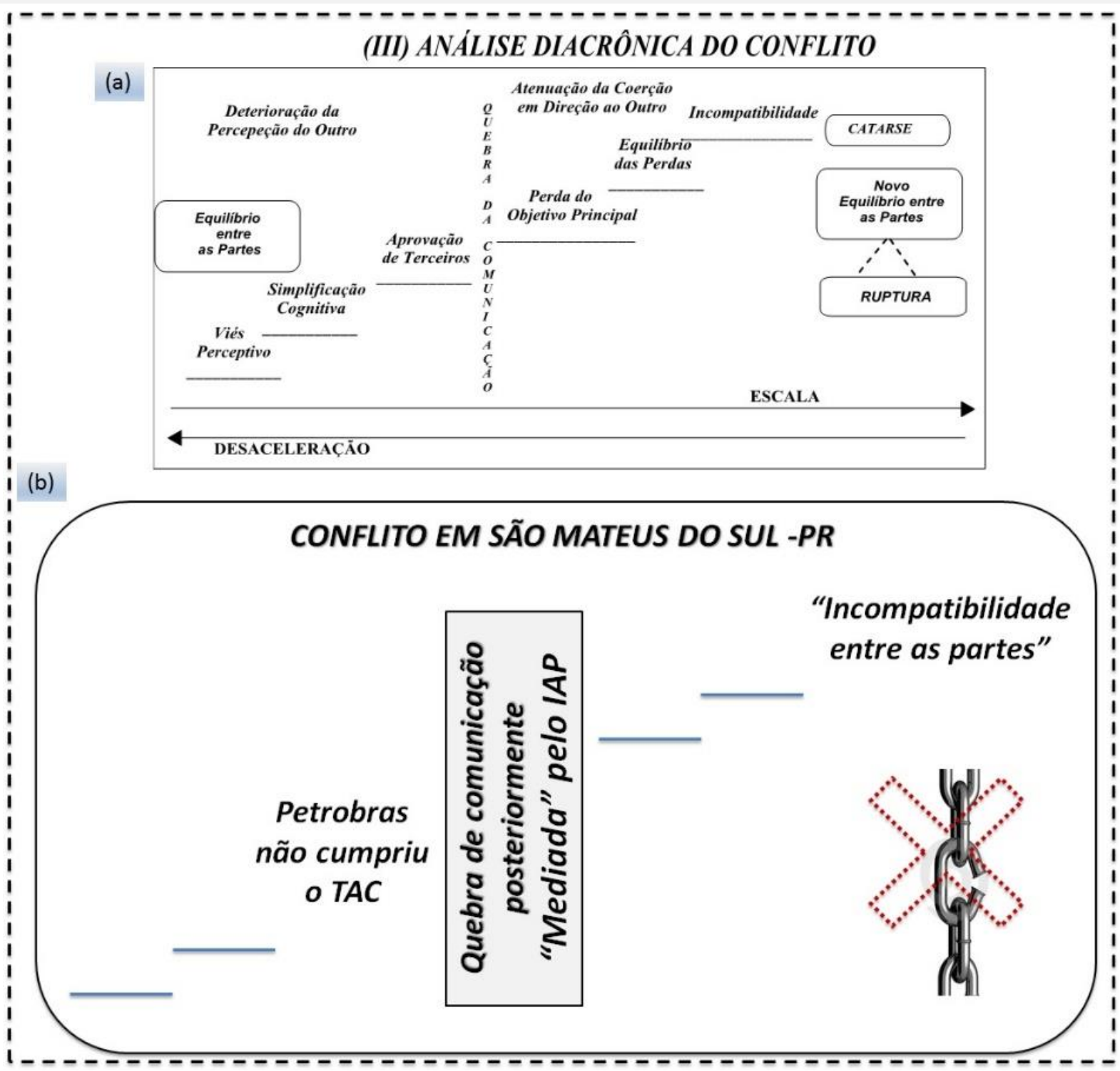

Figura 3 - (a) Análise Diacrônica do Conflito - Rondeau (1996) e (b) Aplicação do modelo ao conflito em de SMS. Fonte: Adaptado de Rondeau (1996).

Segundo Fontoura, Naves, Teosósio \& Gomes (2019), existe uma troca nessas relações de dependência identificadas no parágrafo acima. A comunidade local e o governo dependem da atuação das empresas mineradoras e do capital nelas investido por grandes corporações internacionais, as empresas mineradoras dependem da comunidade local para mão de obra e de suas riquezas ambientais para sua atividade fim.

É oportuno destacar como conflitos socioambientais apresentam uma natureza complexa e seus desdobramentos não terminam em um resultado lógico. Nesse sentido, para uma análise comparativa, apresenta-se brevemente algumas questões acerca do evento catastrófico do rompimento da barragem de rejeitos de Fundão, pertencente à empresa Samarco, localizada em Mariana, Minas Gerais. Na ocasião, cerca de 65 milhões de $\mathrm{m}^{3}$ de rejeitos químicos misturados à lama foram liberados. Acompanhando o curso do rio, a lama percorreu mais de $826 \mathrm{~km}$, prejudicando a qualidade de vida e o desenvolvimento de diversos municípios, em Minas Gerais e Espírito Santo. Além das incontáveis perdas de vidas humanas e espécies da fauna e flora, que foram extintas, os danos ambientais foram irreversíveis no que se refere, principalmente, à atividade pesqueira nos rios e com as atividades de pequenos agricultores que tinham suas roças em locais onde a margem dos rios foi encoberta de lama (Franco, 2015).

Não obstante à grandeza dos impactos ambientais, com o passar dos meses parte dos moradores da cidade, alguns trabalhadores da Samarco, a Prefeitura e muitos comerciantes preocupados com a situação econômica de Mariana começaram uma campanha em prol da reabertura das atividades da Samarco, que se 
intitula "Fica Samarco" (Ferreira \& Saraiva, 2019). Por outro lado, pela magnitude da catástrofe, chama a atenção como a dimensão social - e desenvolvimento econômico - se sobrepõem às questões ambientais, o que de certa forma fortalece o poder de barganha de grandes empreendimentos.

Depreende-se, portanto, que relação da sociedade civil com atividades potencialmente poluidoras é ambígua - de ônus e de bônus. No caso da mineração, os empreendedores exploram essa ambiguidade em seu favor para se furtar à internalização das externalidades negativas que ela gera.

Guardando-se as devidas proporções dos dois casos, as preocupações futuras da sociedade civil, moradores e governantes possuem um forte viés com o medo da estagnação econômica e aumento da disparidade social nas cidades. Para tal realidade, ainda que o caminho mais lógico para análise do conflito, de acordo com o Modelo Diacrônico de Rondeau (1996), seja a ruptura total das negociações entre as partes, ela não se concretizou, pelo menos no caso de SMS. Pode-se ainda afirmar que, em ambas as negociações, é essencial para o país que tem a mineração como um dos pilares da economia que se projete um modelo de desenvolvimento reduzindo a dependência econômica dos municípios, com sustentabilidade ambiental e justiça social.

A Análise Estrutural do Modelo Diagnóstico de Rondeau (Figura 4a), por fazer um raio-X da situação de um conflito, em determinado momento, pode ser usada como um frame de análise, tanto para os conflitos relacionados à poluição ambiental e danos à saúde, como para os conflitos de vizinhança que envolvem desapropriação do solo e fragmentação de relações sociais de pequenos proprietários fundiários.

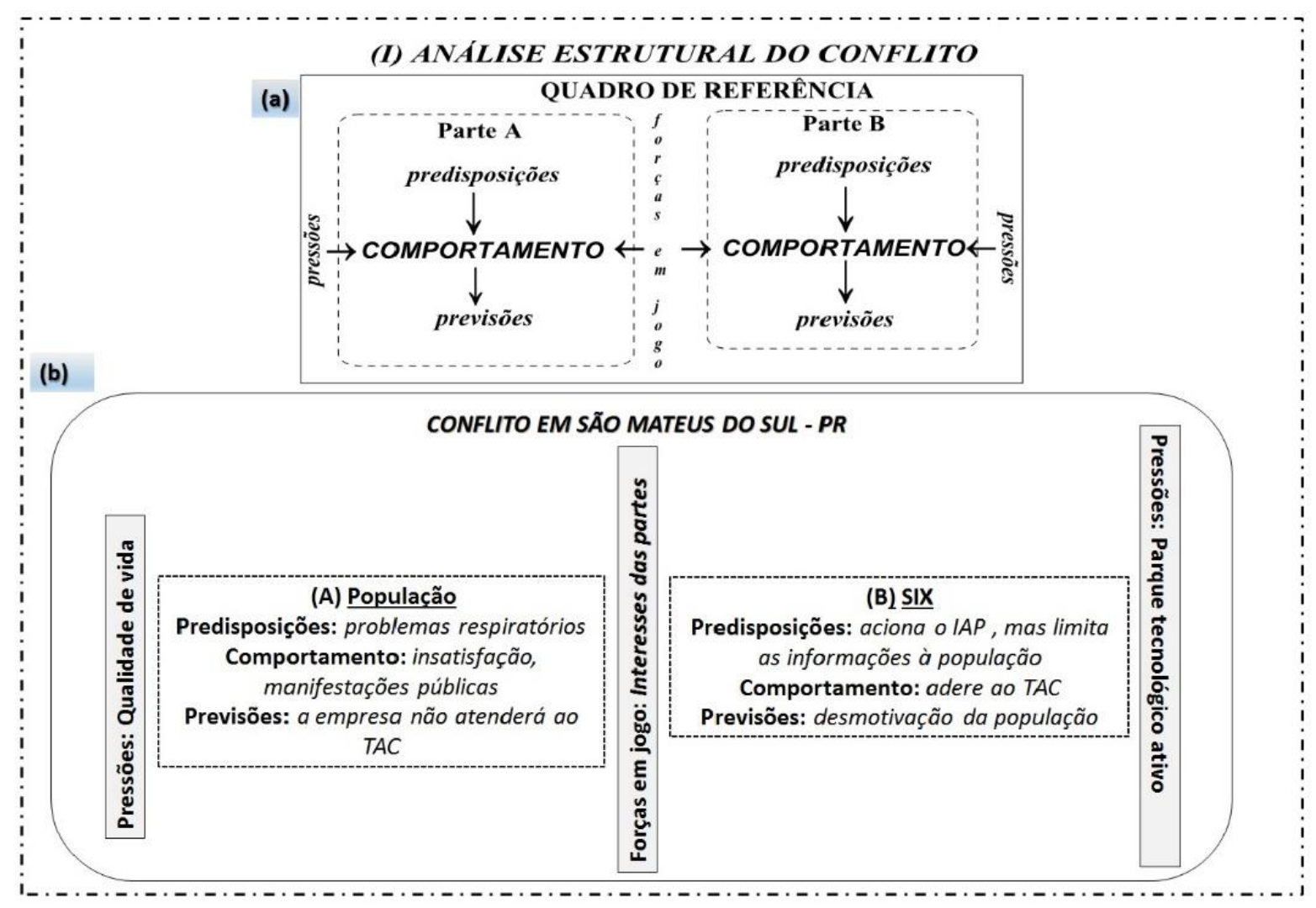

Figura 4 - (a) Análise de Estrutural do Conflito - Rondeau (1996) e (b) Aplicação do modelo ao conflito ambiental em de SMS. Fonte: Adaptado de Rondeau (1996).

Sob o olhar da Análise Estrutural tem-se de um lado a população local que percebeu e se manifestou, em 2000, contrariamente à poluição causada pelas atividades industriais da SIX e a deterioração da qualidade do ar/efeitos na saúde humana. Do outro lado, está a Petrobras que, em 2002, procurou o IAP para comunicar possíveis problemas de contaminação ambiental no interior do complexo industrial. Essa comunicação da Petrobras provavelmente foi motivada pela investigação sobre os danos de poluição à população iniciada pela Promotoria Pública de SMS. Como cabe a Promotoria Pública defender o interesse 
dos cidadãos, esta ação deve ter sido motivada por reclamações por parte da população, que pode ser enxergada no Modelo de Rondeau (1996) como predisposições da Parte A, (Figura 4b).

Assim, a Parte A se caracteriza como pressões da população local, exigindo garantias para remediar om impactos ao meio ambiente e à qualidade de vida. A Parte B representaria os interesses da direção da Petrobras para manter ativo o Parque Tecnológico do SIX (Figura 4b), apoiada pela população que mantém algum vínculo com a empresa. Em função do desequilíbrio das forças em jogo; invariavelmente verificado em cenários onde grandes empreendimentos detêm o poder, a população, prevendo que a Petrobras não responderia aos seus reclamos, se antecipa buscando apoio via Procuradoria Pública.

Embora tenha aderido prontamente ao TAC, verifica-se que a postura da Petrobras (predisposição de B) não foi de todo proativa, pois não estendia a comunicação de problemas de contaminação, feita junto ao IAP, para a população de entorno. Ou seja, percebe-se que a empresa tentava atenuar a dimensão do problema, muito provavelmente prevendo o arrefecimento às pressões da população.

Com a inserção do IAP no processo, propondo um TAC, pelo qual a Petrobras teria que realizar um diagnóstico ambiental para avaliar a extensão do impacto da poluição nos entornos da planta SIX, é possível visualizar o conflito relacionado à poluição e danos à saúde no contexto do Modelo da Análise Dinâmica do Modelo Diagnóstico (Figura 5a). Neste caso, o episódio precedente seria a poluição e a manifestação da população, que antecedeu 2000, mas que se consubstancia em uma ação judicial neste ano, tornando o conflito explícito (Figura 5b).

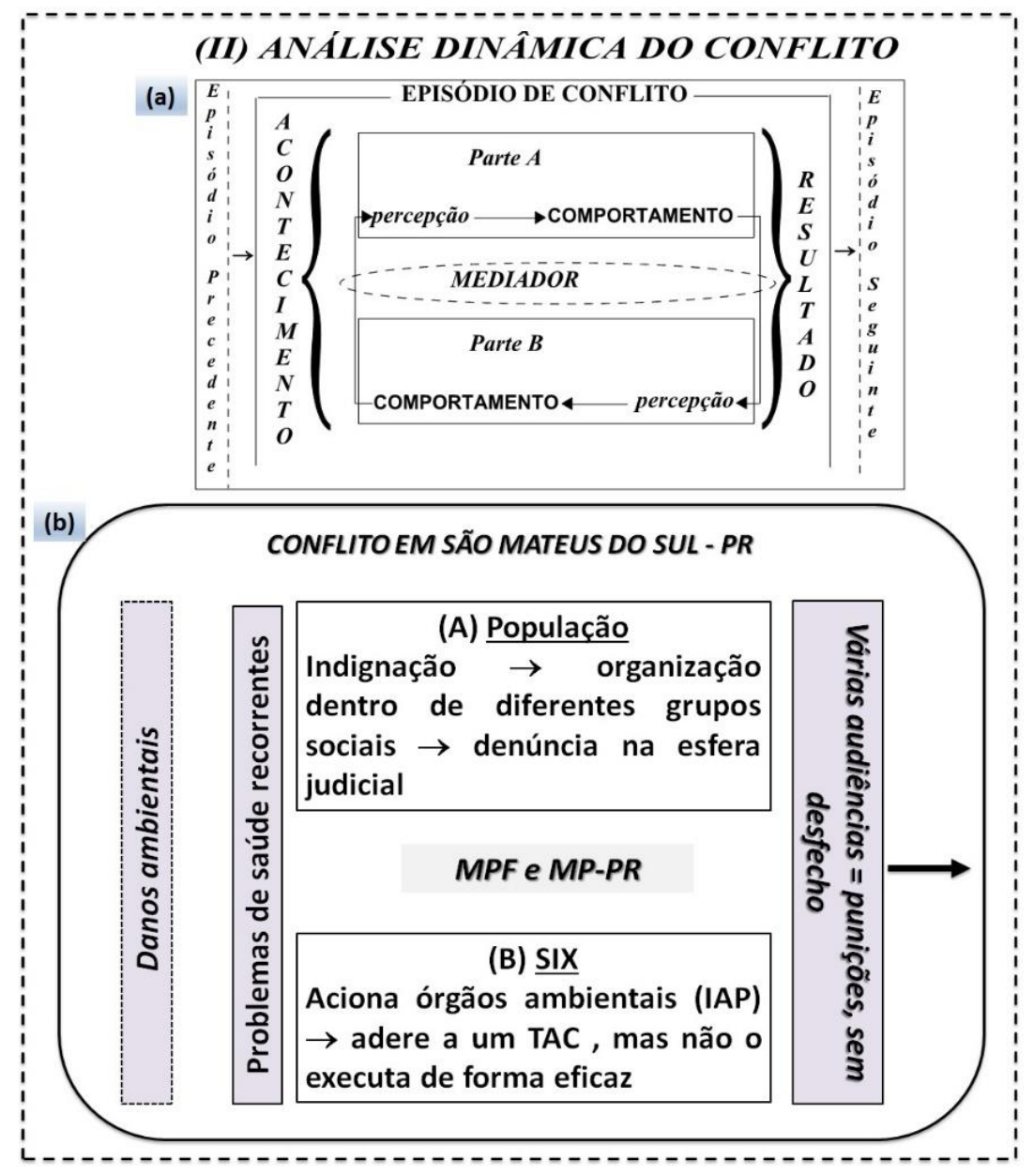

Figura 5 - (a) Análise Dinâmica do Conflito - Rondeau (1996) e (b) Aplicação do modelo ao conflito ambiental em SMS. Fonte: Adaptado de Rondeau (1996).

As observações sobre as predisposições e previsões das partes em embate efetuadas na Análise Estrutural (Figura 4b) valem aqui, porém, dando-se a elas uma conotação dinâmica em que as predisposições e previsões das partes A e B (Figura 5b) se traduzem em percepções e comportamentos que 
se modificam à medida que o conflito evolui. Ou seja, as contínuas interações entre as partes, neste caso, geram um "resultado" que pode ser visto como um episódio seguinte do embate.

O IAP pode ser visto como uma espécie de mediador pelo fato de chamar as partes para uma solução dialogada e concretizada via assinatura de um TAC. Como episódio seguinte, no entanto, observou-se que a Petrobras não cumpriu o TAC, demonstrando desinteresse na condução do conflito pela via extrajudicial. Esta postura chama atenção, pois um TAC pode ser executado, caso não seja cumprido por pelo menos um dos signatários. Ainda como desdobramento deste episódio, em seguida houve o aditamento do TAC e o ajuizamento de ação civil pública em 2004, junto ao MPF, requerida pela ONG AMAR, contra a Petrobras e o IAP. Neste caso, o que se observou foi uma complicação ainda maior do embate, com o envolvimento do IAP no processo, conduzindo a ação para o Judiciário.

Em relação aos conflitos envolvendo desapropriação do solo e fragmentação das relações sociais, o Modelo de Rondeau (1996) permite visualizar os embates de uma forma mais simplificada.

$\mathrm{Na}$ Análise Estrutural tem-se os proprietários fundiários (Parte A) situados nos entornos das quatro minas de xisto operadas pela SIX, com destaque para os agricultores da comunidade Dois Irmãos, que tiveram suas terras desapropriadas por uma dessas minas e a Petrobras (Parte B) como operadora dessas minas. As pressões de A, neste caso, são por um meio ambiente com mais qualidade e pelo "resgate" de relações sociais entre parentes e amigos de comunidade de agricultores que tiveram suas terras desapropriadas pela Mina Dois Irmãos. Tais descontentamentos geraram predisposições de luta e de busca de direitos pela população (Parte $\mathrm{A}$ ), ante as previsões de que Petrobras não atenderia seus anseios e expectativas. A Parte B, pelo interesse em manter a SIX no município (predisposição), dando pouca atenção à população descontente, visa manter o conflito sob certo controle, sem, por exemplo, chamar a atenção de grupos ambientalistas.

Na Análise Dinâmica, o episódio precedente é caracterizado por dois acontecimentos: poluição ambiental causada pelas minas de xisto e fragmentação de laços comunitários pela desapropriação de terras por uma das minas. Transpondo a situação descrita na Análise Estrutural para o contexto da Análise Dinâmica, na ausência de um agente mediador, pode-se dizer que as predisposições e previsões dos atores em embate (interpretação da Análise Estrutural), se traduziram, de um lado, em postura passiva da Petrobras (Parte B) e em ajuizamento de várias ações civis públicas pela população (Parte A). Essas situações podem ser vistas como o "resultado" da dinâmica dos embates sendo que o "episódio seguinte" provavelmente será determinado, pelo menos em parte, pelo julgamento dessas ações.

Pela Análise Dinâmica, ainda cabe destacar que, a proposição de Watanabe (2010) de uma gestão ambiental participativa, fundamentada nos princípios da Agenda 21 Local, para minimizar os impactos sobre as famílias desapropriadas, se aproxima do que se esperaria de um agente mediador para a busca de uma solução negociada para pelo menos a parte do conflito que se remete à comunidade de agricultores.

\section{Discussão}

Dentre os temas recorrentes que tangenciam os conflitos socioambientais está a Responsabilidade Social Empresarial (RSE), entendida como uma referência positiva entre as relações Estado, empresas e sociedade civil (Fontoura et al., 2019). No entanto, a RSE na realidade é uma narrativa ilusória, em prol da perpetuação da hegemonia corporativa (Fontoura et al., 2019). Na visão de Passos, Coelho \& Dias (2017) a degradação ambiental, independentemente de sua magnitude, sempre apresenta uma "história não contada" pela mídia oficial, órgão públicos e empresas. Ainda segundo os autores, apesar da gravidade dessa narrativa ilusória, ainda são incipientes os debates que envolvem universidades e a participação social. Notadamente, essa debilidade se observa também na forma como o Brasil conduz as negociações de conflitos socioambientais (Bernardelli-Junior et al., 2017).

Por outro lado, para a realidade vivenciada atualmente, os instrumentos legais não têm sido suficientes para que se observe a RSE; tampouco a "garantia da integridade do meio ambiente ecologicamente equilibrado". As situações conflituosas decorrentes de danos ambientais não mitigados, como as 
relacionadas à SIX em SMS, em geral são encaminhadas ao Judiciário. A ação civil pública é o instrumento processual que impõe a obrigação de recuperação dos danos causados e/ou o ressarcimento pela reparação.

Sobre essa questão, cabe observar que a legislação ambiental brasileira, mesmo sendo bastante desenvolvida, apresenta-se como restritiva aos negócios. Uma dessas restrições pode ser observada a partir da análise do artigo 225 da Constituição Federal - CF (Brasil, 1988) - Natureza do Bem Ambiental - quando menciona que "todos têm direito ao meio ambiente ecologicamente equilibrado". Essa afirmação, de certa forma, choca-se com as diretrizes da questão da posse da terra e/ou da outorga de direitos de uso dos recursos naturais a ela relacionados, presentes tanto no solo como no subsolo, como visto, por exemplo, com o Código de Mineração (Brasil, 1967). Isso porque, mediante os títulos de propriedade e/ou de concessão de direitos minerários, os titulares, ao explorarem os recursos minerais em questão, geram impactos ambientais nos bens de uso comum (água, ar e solo) que, pela Carta Magna, pertencem ao povo, ou seja, a todos os cidadãos (direito difuso).

Ainda no artigo 225 da CF está explícito que "cabe ao poder público o dever de defender o meio ambiente e à coletividade o de preservá-lo para as presentes e futuras gerações" (Brasil, 1988). Desta afirmação, pode-se inferir que a proteção ao meio ambiente, acima de outras circunstâncias, uma obrigação do Estado (Fontoura et al., 2019; Paes et al., 2011), por ser um bem de uso comum. Portanto, compete à administração pública exercer o princípio da prevenção, a partir de licenças, sanções administrativas, e fiscalização das autorizações aos empreendimentos com potencial de dano ao meio ambiente.

Como forma de contribuição à discussão, o artigo trouxe reflexões sobre os conflitos socioambientais em SMS, a partir de diferentes olhares, baseando-se nos Modelos Diagnótico de Rondeau (1996), que se constituem em frames de análise que possibilitam aos negociadores e/ou às partes envolvidas interessadas na gestão do conflito a entenderem as origens, evoluções e consequências dos embates, de modo a orientar suas formas de agir, levando em conta as suas características e a enxergar possíveis maneiras de solucionálos ou de reduzir os seus impactos sobre as partes envolvidas. Ou seja, essas abordagens podem ajudar no entendimento dos conflitos e de suas negociações, porém, não se traduzem em mecanismos de negociação em si.

No que tange às negociações de conflitos ambientais, em função de suas complexidades, os atuais mecanismos de negociação ainda são incapazes de garantir a resolução consensual. Corrobora esta informação a análise do conflito não estritamente sob a ótica do Direito Ambiental, podendo-se afirmar que meio ambiente parece ser relegado a um segundo plano, não sendo reconhecido efetivamente como bem de uso comum que precisa ser protegido. Em outras palavras, embora a decisão do juiz de não acatar a interrupção das atividades da SIX, aparentemente, possa ter favorecido uma dimensão da sustentabilidade (a social) em relação à ambiental, na verdade, ela considerou a dimensão socioambiental pelo fato das duas estarem interconectadas e praticamente indissociadas.

\section{Conclusões}

O conflito socioambiental em SMS, entre outros observados no Brasil, revela o distanciamento do que tem sido fortemente proclamado como um comportamento corporativo ético, social, responsável e ambientalmente consciente de mineradoras, e o que de fato está acontecendo com as pessoas e o meio ambiente em contextos de subalternidade. Atores diretamente afetados pelas atividades de exploração, como populações tradicionais, pequenos agricultores, moradores, entre outros, têm sido histórica e socialmente ignorados das estratégias de responsabilidade social e empresarial indicadas por grandes incorporadoras. Há de se destacar, entretanto, que em termos ecológicos, essas pessoas são geralmente as mais afetadas, devido às pressões sob sistemas planetários e pelas consequências negativas da mudança climática.

Por outro lado, para que a sociedade possa, de fato, exigir de suas autoridades o cumprimento do compromisso assumido pelo Brasil, com a qualidade de vida e a preservação do meio ambiente, seria preciso uma mudança drástica na base econômica do país, com a completa substituição da exploração de recursos 
naturais, por uma atividade primária que contemple alternativas renováveis. Para Sollow (1993) isso é praticamente impossível.

Outra ponderação cabível é que mesmo sendo os juízes extremamente legalistas em matéria ambiental, em situações como a da SIX, a tendência de suas decisões é priorizar os interesses coletivos, neste caso o emprego das pessoas. A inexistência de informações sistematizadas sobre doenças provocadas ou agravadas por problemas de poluição, provavelmente corroborou com a decisão do juiz no caso em questão. Isso pode ser observado na sua ponderação de que mesmo após investigações encaminhadas por solicitação do MP-PR, desde 2002, nenhuma comprovação de danos irreversíveis ao meio ambiente e à saúde humana foi registrada.

Pode-se afirmar que as dificuldades decisórias em relação à busca de soluções para conflitos socioambientais, em parte, refletem a falta de utilização sistemática do planejamento ambiental na fase precedente ao licenciamento ambiental dos empreendimentos, etapa de gestão em que a consulta, os debates de esclarecimento e a composição de interesses podem ser incorporados naturalmente, por disponibilidade de tempo necessário a este tipo de empreendimento.

No entanto, considerando a situação socioeconômica de SMS, à época da implantação do empreendimento, é difícil imaginar o quanto a disseminação de informações sobre os seus impactos ambientais teria reflexo no licenciamento da unidade de exploração de xisto.

Novamente, vem à luz o poder do setor de mineração, ao desafiar os limites das sociedades nas quais estão inseridas. As mineradoras transferem tanto em curto quanto em médio e longo prazos os custos incalculáveis de suas ações para a sociedade, negando-se a assumir suas responsabilidades. Convém destacar que o conflito de SMS arrola na justiça desde o início dos anos 2000 e passados vinte anos, nenhum desfecho foi verificado.

Com a promulgação da Carta Magna de 1988, o meio ambiente tornou-se um ente tutelado pelo Estado, sendo objeto de uma quantidade considerável de embates encaminhados para a esfera jurisdicional, fenômeno esse que muito provavelmente limitou a produção científica em negociação de conflitos ambientais no país. Some-se a isso a quase inexistente utilização de técnicas de negociação oriunda da literatura internacional (Shamir, 2003)

Por fim, o emprego de modelos teóricos, para entendimento das etapas que se revelam a partir de episódios precedentes no caso de SMS e tantos outros, como o Modelo Diagnóstico de Rondeau (1996), pode contribuir para vislumbrar formas diferenciadas de mediações de conflitos que possam ser estabelecidas entre os atores envolvidos, a exemplo do que se verifica nos Estados Unidos e Canadá, com a obrigatoriedade da criação de fundos de compensação. Esses fundos são considerados modelos de usos sustentáveis das rendas da exploração de petróleo e gás natural e visam proporcionar melhorias, de curto e longo prazo, principalmente às comunidades afetadas pelas plantas de mineração (Enríquez, 2006).

\section{Referências}

Aníbal, F. (07 de fevereiro de 2013). Justiça nega liminar Petrobras. Gazeta do povo. Recuperado em 23 de abril de 2015 , de https://www.gazetadopovo.com.br/vida-e-cidadania/justica-nega-liminar-que-fecharia-usina-de-xisto-da-petrobrasbakzt8be6bc77ggpautoxhtza/\#comentarios

Araújo, L. A. (1999). Perícia ambiental em ações civis públicas. In S. C. Guerra, Avaliação e perícia ambiental (pp. 174-215). Rio de Janeiro: Bertrand Brasil.

Acselrad, H. (2004). Introdução. Em H. Ascelard, Conflitos ambientais no Brasil (pp. 7-36). Rio de Janeiro: Relume Dumará.

Bernardelli-Junior, J.M., Ruiz, M. S., \& Gallardo, A. L. (2017). Conflitos Socioambientais na APA Bororé-Colônia: Dos Preexistentes aos Novos Associados ao Licenciamento Ambiental do Trecho Sul do Rodoanel de São Paulo. Desenvolvimento em Questão, 15(40), 104-139.

Braga-Neto, A. (2008). Mediação de Conflitos e Políticas Públicas-A Experiência com a Mediação Comunitária em Distritos de Alta Vulnerabilidade da Grande São Paulo. Revista Brasileira de Arbitragem, 5(18). 
Brasil. (1967). Decreto - Lei Fedral 227. Código de Minas. Recuperado em 20 de março de 2015, de http:// http://www.planalto.gov.br/ccivil_03/decreto-lei/del0227.htm

Brasil. (1981). Lei Fedral 6.938. Política Nacional do Meio Ambiente. Recuperado em 20 de março de 2015, de http://www.planalto.gov.br/ccivil_03/constituicao/constituicaocompilado.htm

Brasil. (dez de 1985). Lei n. 7.437, 20 de dezembro de 1985. Lei n. 7.437. Disciplina a ação civil pública de responsabilidade por danos causados ao meio-ambiente, ao consumidor, a bens e direitos de valor artístico, estético, histórico, turístico e paisagístico (VETADO) e dá outras providências. Recuperado em 20 de março de 2015, de http://www.planalto.gov.br/ccivil_03/LEIS/L7347orig.htm

Brasil. (1988). Constituição federal, 1988. Presidênsia da República - Casa Civil. Recuperado em 20 de março de 2015, de http://www.planalto.gov.br/ccivil_03/constituicao/constituicaocompilado.htm

Bredariol, C. S. (1997). Conflitos Socio-Ambientais no Rio de Janeiro. In Limoncic, F. \& Scotto, G. Conflitos Socio-Ambientais no Brasil. (Vol. 2). Rio de Janeiro: IBASE.

Bredariol, C. S. (2001). O conflito ambiental e negociação para uma política local de meio ambiente. (Tese de doutorado). Universidade Federal do Rio de Janeiro, Rio de Janeiro.

Bredariol, C. S. (2004). 0 aprendizado da negociação em conflitos ambientais. In Anais do Encontro Nacional de PósGraduação e Pesquisa em Ambiente e Sociedade. Indaiatuba.

Bredariol, C. S. ,\& Magrini, A. (2003). Conflicts in developing countries: a case study from Rio de Janeiro. Environmental Impact Assessment Review, 23(4), 489-513.

Camargo, S. (2007). Mediação ambiental. Jornal do Instituto de Engenharia, 4(39), 13-13.

Chagas, M. (2010). Conflitos, gestão ambiental e o discurso do desenvolvimento sustentável da mineração no Estado do Amapá. (Tese de doutorado). Universidade Federal do Pará, Programa de Pós-Graduação em Desenvolvimento Sustentável do Trópico Úmido, Belém.

Corrêa, R. (2015). Gestão dos conflitos socioambientais de subsidência de minas de carvão em Santa Catarina: uma proposta de modelo para suporte de negociações. (Tese de doutorado) Universidade Nove de julho, São Paulo.

Costa, G. V. (2011). As reservas biológicas como mecanismo de controle estatal. Revista de Sociologia e Política, 19(38), 159170.

CPRM. (2005). Projeto APA Sul RMBH. Estudo do meio físico.

Cunha, I. (2006). Oficina de negociação ambiental. Material de apoio Petrobras.

Dias, G. F. (2000). Educação Ambiental: princípios e práticas. São Paulo: Gaia.

Dias, H., \& Padovan, P. (1995). Mata Atlântica: o Estado do Espírito Santo. In Carvalho, I., \& Scotto, G. Conflitos Ambientais no Brasil. Rio de Janeiro: IBASE.

Enríquez, M. (2006). Equidade intergeracional na partilha dos benefícios dos recursos minerais: a alternativa dos Fundos de Mineração. Revibec: Revista Iberoamericana de Economía Ecológica, 5, 61-73.

Ferreira, A. B., Ribeiro, A. P., Ferreira, M. L., Kniess, C. T., Quaresma, C. C., Lafortezza, R., Santos, J. O., Saiki, M., Saldiva, P. H. (2017). A streamlined approach by a combination of bioindication and geostatistical methods for assessing air contaminants and their effects on human health in industrialized areas: a case study in Southern Brazil. Frontier in Plant Science, 8, 1575.

Ferreira, P. M., \& Saraiva, C. M. (2019). A catástrofe como perpetuadora da sociedade unidimensional. Farol: Revista de estudos Organizacionais e Sociedade, 6(15), 42-78.

Figueiredo, B. R., De Capitani, E. M., Anjos, J. A., \& Luiz-Silva, W. (2012). Chumbo, ambiente e saúde (1. ed.). São Paulo: Annablume.

Fisher, R., \& Ury, W. Como chegar ao sim: a negociação de acordo sem concessões. 1 ed. Rio de Janeiro: Imago, 1985.

Fisher, R., Ury, W. L., \& Patton, B. (2011). Getting to yes: Negotiating agreement without giving in. New York: Peguin Books, 240 p.

Fontoura, Y., Naves, F., Teodósio, A.D.S., \& Gomes, M. V. P.(2019). “Da Lama ao Caos”: reflexões sobre a crise ambiental e as relações Estado-Empresa-Sociedade. Farol: Revista de Estudos Organizacionais e Sociedade, 6(15), 17-41. 
Franco, A. (2015). Danos ambientais são irreversíveis, avalia ambientalista. In 0 Tempo. Recuperado em 01 de dezembro de 2020, de http://www.otempo.com.br/cidades/danosambientais-s\%C3\%A3o-irrevers\%C3\%ADveis-avaliaambientalista-1.1161447.

Fuks, M. (1998). Arenas de Ação e Debate Públicos: Conflitos Ambientais e a Emergência do Meio Ambiente enquanto Problema Social no Rio de Janeiro. Dados, 41(1).

Galvão-Filho, J. (2001). A gestão de conflitos socioambientais no uso dos recursos natur. Revista Banas Ambiental, 2(11).

Herculano, S. (2002). Resenhando o debate sobre justiça ambiental: produção teórica, breve acervo de casos e criação da rede brasileira de justiça ambiental. Desenvolvimento e Meio Ambiente(5), 143-149.

IBASE. (2003). Descortinando o Brasil: justiça ambiental. Instituto Brasileiro De Análises Sociais e Econômicas.

IBGE. (2010). Censo 2010. (I. B. Estatistica, Produtor, \& IBGE). Recuperado em 11 de fevereiro de 2019, de http://www.cidades.ibge.gov.br/xtras/perfil.php?codmun=355030\%26search=sao-paulo|sao-paulo\&lang

Jacobi, P. R. (1995). Diagnóstico de conflitos sócio-ambientais na cidade de São Paulo. São Paulo: CEDEC.

Jacobi, P., \& . Teixeira, M. (1995). Questão Urbana: a cidade de São Paulo. Em I. Carvalho, \& G. Scotto, Conflitos Ambientais no Brasil (Vol. 1). Rio de Janeiro: IBASE.

Little, P. E. (2001). Amazonia: territorial struggles on perennial frontiers (1 ed.). Baltimore: Johns Hopkins University Press. Miranda, A. (2011). Mecanismos de compromisso de ajuste (Vol. 7). Belo Horizonte: IETEC.

MPE-PR. (2013). Petição Inicial de Ação Civil Pública. Promotora de Justiça: Fernanda B. Silvério.

Nascimento, E. (2001). Os conflitos na sociedade moderna: uma introdução conceitual. In Bursztyn, M. A difícil sustentabilidade: política energética e conflitos ambientais. Rio de Janeiro: Garamond.

Oliveira Neto, R., \& Petter, C. (2005). A abordagem da economia ambiental no contexto da mineração. Revista Escola de Minas, 58(1), 71-75.

Paes, J. (2011). Artigos. Recuperado em 23 de abril de 2015, de https://www.jurisway.org.br/v2/dhall.asp?id_dh=6273

Passos, F. L., Coelho, P., \& Dias, A. (2017). (Des) territórios da mineração: planejamento territorial a partir do rompimento em Mariana, MG. Cadernos Metrópole, 19(38), 269-297.

Petrobras. Unidade de industrialização do xisto (SIX). Informe Petrobras, 2009. Recuperado em 20 de abril de 2015 de http://www.petrobras.com.br/pt/nossas-atividades/principais-operacoes/refinarias/unidade-de-industrializacao-doxisto-six.html

PMSMS - Prefeitura Municipal de São Mateus do Sul. Recuperado em 12 de abril de 2015 de http://www.saomateusdosul.pr.gov.br/o-municipio/

Rech, H. (2010). Relatório São Mateus do Sul. Campinas: Relatório UNICAMP.

Ribeiro, A. P., Ferreira, A. B., Aquino, S., Rodriguez, Kniess, C. K., Quaresma, C.C, \& Saldiva, P. H. (2017). Diagnóstico da poluição atmosférica em regiões sem redes convencionais de monitoramento da qualidade do ar: estudo em uma pequena cidade do Paraná, Brasil. Interciencia, 42(11), 767-773.

Rocha, D. F. (2012). Um Brasil de conflitos - conheça o mapa de injustiça ambiental e saúde no Brasil. EcoDebate, Cidadania \& Meio Ambiente.

Rondeau, A. (1996). A gestão dos conflitos nas organizações. In Chanlat, J. F. O indivíduo na organização: dimensões esquecidas. São Paulo: Atlas.

Ruiz, M. S., Correa, R., Gallardo, A. L., \& Sintoni, A. (2014). Abordagens de conflitos socioambientais em casos de subsidência de minas de carvão no Brasil e EUA. Ambiente \& Sociedade, 17(2), 129-156.

Schmitt, C. (1995). Mata de Araucárias: a região norte do Rio Grande do Sul. In Carvalho, I. \& Scotto, G. Conflitos Ambientais no Brasil. Rio de Janeiro: IBASE.

Shamir, Y. (2003). Alternative dispute resolution approaches and their application. ICNM. UNESCO.

Silva, K. O. (jan./mar. de 2007). A periferização causada pela desigual urbanização brasileira. Revista Urutágua, 1-8.

Sollow, R. (1993). An Almost Practical Step Toward Sustainability. Resources Policy, 19(3), 162-172. 
TJ-PR. (2006). Processo Eletrônico do Judiciário do Paraná no 338-13.2013.8.16.0158. Recuperado em 26 de março de 2015, de https://projudi.tjpr.jus.br/projudi/

Viégas, R. (2009). Conflitos ambientais e lutas materiais e simbólicas. Desenvolvimento e Meio Ambiente, 19, $145-157$.

Villas-Boas, R. (1995). São Paulo: Conflitos e Negociações na Disputa Pela Cidade. São Paulo: Polis.

Watanabe, C. (2010). Impactos ambientais da mineração do folhelho pirobetuminoso nos meios físico e antrópico em São Mateus do Sul, Paraná. (Tese de doutorado). Rio Claro: UNESP.

Weiss, J. S. (org.) (2019). Movimentos socioambientais: lutas - avanços - conquistas - retrocessos - esperanças. 1. Ed. Formosa: Xapuri Socioambiental. $442 \mathrm{p}$.

Werner, T. T., Bebbington, A., \& Gregory, G. (2019). Assessing impacts of mining: Recent contributions from GIS and remote sensing. The Extractive Industries and Society, 6(3), p. 993-1012.

Wondolleck, J., Manring, N., \& Crowfoot, J. (1996). Teetering at the top of the ladder: The experience of citizen group participants in alternative dispute resolution processes. Sociological Perspectives, 39(2), 249-262.

Yin, R. K. (2010). Estudo de caso: planejamento e métodos (4 ed.). Porto Alegre: Bookman.

Editor: Harry Bollmann

Recebido: 03 set. 2020

Aprovado: 18 jan. 2021 